\title{
Павел Сивохин
}

\section{Max Besbris. Upsold: Real Estate Agents, Prices, and Neighborhood Inequality. Chicago: University of Chicago Press, 2020. 208 pp. ISBN 978-0-226-72137-8.}

Павел Сивохин, Научно-учебная лаборатория социальных исследований города, факультет городского и регионального развития Национального исследовательского университета «Высшая школа экономики». Адрес для переписки: НИУ ВШЭ, Мясницкая ул., 13, стр. 4, каб. 314, Москва, 101000, Россия. psivokhin@hse.ru.

Книга Макса Бесбриса «Продано: Агенты по недвижимости, цены и межрайонное неравенство» рассказывает о том, как устроен рынок жилья в США, и о тех, кто на него влияет. Автор предлагает рассматривать желания и предпочтения покупателей на рынке жилья как подвижные и постоянно изменяющиеся в ходе переговоров. Участие в сделках посредников, агентов по недвижимости, брокеров, банковских служащих, предоставляющих кредиты на приобретение жилья, является, по мнению Бесбриса, ключевым фактором этих изменений. Автор берется объяснить, как именно взаимодействие с рыночными посредниками влияет на продавцов и покупателей недвижимости и каким образом все это способствует воспроизводству жилищного неравенства в Нью-Йорке.

Книгу Бесбриса справедливо будет отнести сразу к нескольким исследовательским областям. Работа во многом опирается на экономические исследования, которые описывают поведение покупателей на рынке жилья, однако автору все же не удалось систематизировать предшествующие исследования и выстроить теоретическую рамку, объясняющую изменение поведения покупателей при взаимодействии с агентами по недвижимости. Уместным, мне кажется, было бы обращение к другому примеру анализа в области поведенческой экономики - работе Даниэля Канемана и Амоса Тверски «Choices, Values, and Frames» (2020), описывающей процесс принятия решений в условиях ограниченной информации.

Несмотря на то, что значительная часть книги посвящена экономическому поведению, главной задачей работы является изучение жилищного неравенства в США. Здесь автор не просто рассматривает жилищных агентов как тех, кто влияет на усиление неравенства, а включает их деятельность в более широкий контекст. Вслед за другими исследователями (например: Beer et al. 2011) Бесбрис анализирует влияние на формирование неравенства на рынке жилья таких факторов, как рыночные условия, экономические кризисы, политические и правовые режимы. Таким образом, представленная книга позволяет взглянуть прежде всего на то, какую роль играют агенты по недвижимости в процессе производства неравенства, и понять, как их действия отражаются на уже существующих структурных условиях.

Наряду с широким контекстом исследования, работа опирается и на более частные концепции. Так, автор обращает внимание на значимость образа районов (и конкретнее - районов Нью-Йорка) при покупке жилья. Феномен формирования образа района и его роли уже описан в научной литературе (например: Galster 2012), однако автору удается еще и объяснить, какую роль в формировании таких 
образов играют агенты по недвижимости и как в результате воспроизводится неравенство между районами.

В целом автор ставит перед собой ряд исследовательских вопросов: как появляются жилищные предпочтения у покупателей на рынке недвижимости? как потребители решают, что определенные товары и услуги соответствуют своей стоимости? как эти решения объединяются в более широкие рыночные модели и порождают неравенство? какую роль в формировании жилищных предпочтений играют агенты по недвижимости? Чтобы ответить на эти вопросы, Бесбрис предпринял масштабное исследование, в котором интервью с покупателями жилья и агентами по недвижимости сочетаются с включенным наблюдением, проведенным на специализированных курсах для агентов по недвижимости. Результаты, полученные социологическими методами, подкрепляются статистическими данными: автор строит ряд регрессионных моделей, основанных на данных о локализации деятельности агентов по недвижимости, стоимости жилья и ее изменении в Нью-Йорке с течением времени.

Последовательно описывая роль агентов по недвижимости в процессе принятия решений, автор обращает внимание на средства, благодаря которым риелторы обретают свой статус. Именно этому посвящена первая глава исследования. В ситуации, когда они перестают быть единственными обладателями знания о рынке жилья из-за роста популярности сайтов по поиску недвижимости, агенты вынуждены искать все новые аргументы для своего присутствия на рынке. В процессе взаимодействия с клиентами агенты не только описывают сайты по поиску недвижимости как малонадежные и неточные, но и указывают на низкий уровень профессионализма других агентов по недвижимости, подчеркивая ценность своей экспертизы. Они объясняют свою деятельность не экономической заинтересованностью, а желанием помочь клиенту выбрать идеальный для него вариант жилья. Другими словами, они солидаризируются с клиентом, в то время как на самом деле являются активными агентами влияния, формирующими у клиента мнение о жилье.

Вторая глава рассказывает об инструментах, которыми пользуются агенты. Одним из наиболее популярных приемов является описание района, в котором покупатель собирается приобрести жилье. Рассказывая о преимуществах и недостатках дома или квартиры, агенты апеллируют к образам и идентичностям проживающих в этом районе людей. Вместе с недвижимостью они продают образ места и районную идентичность жителей, определяя район как подходящий для одних типов жителей, но не подходящий для других. Таким образом, агенты по недвижимости участвуют в транслировании образа места. Привлеченные ими покупатели из определенных классов и групп становятся участниками формирования районной идентичности.

В третьей главе автор фокусируется на том, как агенты по недвижимости влияют на принятие решений о покупке жилья, и как взаимодействие агентов и покупателей в свою очередь способствует удорожанию стоимости жилья. Здесь же подробно описаны различные группы потребителей. Автор показывает, что более богатые участники сделок с недвижимостью переплачивают значительно больше, чем покупатели со средним достатком. Такие выводы подтверждаются и анализом приведенным автором статистических данных. 
В последней части книги Бесбрис отмечает, что действия агентов приводят к концентрации более обеспеченных покупателей в определенных районах города. Благодаря агентам сумма сделки повышается, что ведет к росту цен на недвижимость и усиливает районную сегрегацию.

Изучение того, как агенты по недвижимости направляют покупателей в процессе поиска жилья, дает представление о принятии экономических решений и свидетельствуют о месте рыночных посредников в формировании вкусовых предпочтений. Агенты влияют как на предпочтения покупателей, так и на цены, которые покупатели (благодаря агентам) считают приемлемыми.

Автор выясняет, что, во-первых, жилищные предпочтения потребителей в НьюЙорке изменчивы, нестабильны и зависят от рыночного контекста, а также воли агентов по недвижимости; во-вторых, агенты по недвижимости, участвуя в этих отношениях, сами являются апологетами неравенства между районами Нью-Йорка.

Книга Бесбриса вносит значительный вклад в изучение рынка жилья в США. Однако недостатком этой работы, мне кажется, является ее прикладной характер. Книга не позволяет вписать полученные результаты в более широкий теоретический и эмпирический контекст. Тем не менее, несмотря на эмпирическую направленность этой работы и ряд ограничений, связанных с географией исследования, рассматриваемыми группами и процедурой покупки жилья, книга Бесбриса существенно помогает в понимании функционирования рынка жилья и взаимодействия на нем разных участников, включая покупателей и агентов по недвижимости. Более того, в своем исследовании Бесбрис выводит из тени важных городских агентов, которые не только влияют на воспроизводство неравенства на рынке жилья, но и участвуют в формировании социальных отношений и соседства в отдельных районах города. Эта работа может быть полезна и при исследовании взаимодействий на других рынках - например, аренды жилья. Важно и то, что сам дизайн исследования может быть использован для изучения рынков жилья в других странах. Методика, которую использует автор, позволяет зафиксировать особенности конфигурации основных агентов на рынке жилья и инструменты, которыми они пользуются. Однако для этого необходимо дать точное определение агентам по недвижимости, ведь на разных рынках они могут выполнять специфичные функции, отчего их роли будут значительно различаться. Особенно интересной кажется попытка предпринять исследование такого рода в России, где большую роль в жилищных вопросах играет государство и девелоперы.

\section{СПИСОК ЛИТЕРАТУРЫ}

Beer, Andrew, Debbie Faulkner, Chris Paris, and Terry Clower. 2011. Housing Transitions through the Life Course: Aspirations, Needs and Policy. Bristol, UK: Policy Press.

Galster, George. 2012. “Neighborhoods and Their Role in Creating and Changing Housing." Pp. 84106 in The SAGE Handbook of Housing Studies, ed. by David F. Clapham, William A. V. Clark, and Kenneth Gibb. London: SAGE.

Kahneman, Daniel, and Amos Tversky, eds. 2000. Choices, Values, and Frames. New York: Cambridge University Press. 